\title{
Continuing professional development
}

\section{Childhood mental illness}

\author{
Nisha Dogra BM DCH MA PhD FRCPsych \\ Professor of Psychiatry Education and Honorary Consultant in Child and Adolescent Psychiatry, \\ Greenwood Institute of Child Health, University of Leicester, Leicester, UK
}

\section{What is mental health?}

Mental health is as important as physical health. According to the Mental Health Foundation, 'Being mentally healthy does not just mean that you do not have a mental health problem. If you're in good mental health, you can:

- make the most of your potential

- cope with life

- play a full part in your family, workplace, community and among friends? (www.mentalhealth.org. uk/help-information/an-introduction-to-mentalhealth/what-is-mental-health).

\section{What is mental ill health?}

Mental ill health is usually divided into two categories and classified to enable professionals to refer people for appropriate care and treatment. However, some diagnoses are controversial, and there is much concern in the mental health field that people are too often treated according to or described by their label. This can have a profound effect on their quality of life. Nevertheless, diagnoses remain the most usual way of dividing and classifying symptoms into groups.

According to the Mental Health Foundation, 'Mental health problems range from the worries that we all experience as part of everyday life to serious long-term conditions. The majority of people who experience mental health problems can get over them or learn to live with them, especially if they get help early on' (www.mentalhealth.org.uk/help-information/anintroduction-to-mental-health/what-are-mentalhealth-problems).

According to the World Health Organization, mental disorders comprise 'a broad range of problems, with different symptoms. However, they are generally characterised by some combination of abnormal thoughts, emotions, behaviour and relationships with others. Examples are schizophrenia, depression, mental retardation and disorders due to drug abuse. Most of these disorders can be successfully treated' (www. who.int/topics/mental_disorders/en).

\section{Mental ill health in children}

Signs of mental health problems in children include feeling unusually sad, unhappy or worried, or showing behavioural problems. Around $20-25 \%$ of children may develop a mental health problem at some point.

Mental disorders in children are more severe and complex than mental health problems. Some disorders may have a biological basis. Signs of disorder may include self-harming, destructive behaviour, other behavioural problems, severe depression or even psychosis. Around $10-15 \%$ of children may develop a mental health disorder.

Rates of both mental health problems and mental disorders are up to three times higher in deprived areas and among children with multiple needs and/or at high risk (e.g. looked after children, young offenders).

Causes of mental health problems and disorders in children may be related to biological, psychological and/or social factors (see Table 1).

However, it is important to emphasise that only rarely do single factors lead to specific problems. Much more often there is a complex interplay between several risk factors, such as those listed in Table 1.

\section{Helping children with mental health problems and disorders}

Children have to be viewed in the context of their culture and of their families, on whom they are generally dependent, bearing in mind that definitions and compositions of families are changing all the time. Cultural mismatches between young people and their 
Table 1 Factors associated with mental health problems and disorders in children

\begin{tabular}{lll}
\hline Biological factors & Psychological factors & Social factors \\
\hline Genetic & $\begin{array}{l}\text { Temperament/emotional issues } \\
\text { Attachment issues }\end{array}$ & $\begin{array}{l}\text { Socio-economic disadvantage } \\
\text { Parental mental illness }\end{array}$ \\
& Cognitive issues & $\begin{array}{l}\text { Parenting issues/loss of parent(s) } \\
\text { Biochemical }\end{array}$ \\
& $\begin{array}{l}\text { Other environmental factors such as } \\
\text { family, school or peer relationships }\end{array}$ \\
& $\begin{array}{l}\text { Abuse (physical, sexual and/or } \\
\text { emotional) } \\
\text { Neuro-developmental }\end{array}$ & $\begin{array}{l}\text { Exposure to conflict or violence in the } \\
\text { family or wider community }\end{array}$
\end{tabular}

carers may affect both their access to mental health services and the management of their mental health problems or disorder. Any child from any background can develop mental health problems.

Children do not and usually cannot obtain help for or by themselves, but have to depend on someone else to seek help on their behalf.

\section{What helps to promote good mental health among children?}

Secure relationships are very important. They provide stability and form a basis for the development of positive self-esteem. Making friends, playing, having fun and finding things to laugh about all help children to relax, develop coping skills, solve problems and achieve. Physical exercise can also help, so long as it is something that the child enjoys. Eating sensibly and getting adequate sleep are also helpful. When everyday problems arise, these positive factors can help to develop a thoughtful, compassionate attitude to the self, and therefore promote good mental health.

\section{How to promote good mental health in children}

Promoting good mental health in children can be undertaken in many different contexts and by using a range of methods. It will also depend on a range of intersectoral strategies. The World Health Organization has suggested the following specific ways to promote mental health in children:

- 'early childhood interventions (e.g. home visits for pregnant women, pre-school psychosocial activities, combined nutritional and psychosocial help for disadvantaged populations)
- support for children (e.g. skills building programmes, child and youth development programmes)

- programmes targeted at vulnerable groups, including minorities, indigenous people, migrants and people affected by conflicts and disasters (e.g. psychosocial interventions after disasters)

- mental health promotional activities in schools (e.g. programmes supporting ecological changes in schools and child-friendly schools)

- community development programmes (e.g. 'Communities That Care' initiatives, integrated rural development)' (www.who.int/mediacentre/fact sheets/fs220/en).

\section{FURTHER READING}

Bailey S and Shooter M (eds) (2009) The Young Mind. London: Bantam Press.

Dogra N, Parkin A, Gale F et al (2009) A Multidisciplinary Handbook of Child and Adolescent Mental Health for Front-Line Professionals, 2nd edn. London: Jessica Kingsley Publishers.

Both of these texts are written for non-specialist audiences.

\section{USEFUL WEBSITES}

The Royal College of Psychiatrists (www.rcpsych. ac.uk) provides advice and information about mental health and how to obtain help for people with mental health problems and/or disorders.

Mind (www.mind.org.uk) provides advice, information and support for people with mental health problems and/or disorders. It also campaigns to improve services and promote understanding of mental health issues.

The Mental Health Foundation (www.mentalhealth. org.uk) promotes better understanding of mental 
health and mental ill health through research and the utilisation of research findings to improve lives.

The Word Health Organization (www.who.int/ mental_health/en) provides information about mental health issues across the world. The reader is referred in particular to the Mental Health Action Plan 20132020 (http://apps.who.int/iris/bitstream/10665/89966/ 1/9789241506021_eng.pdf).

\section{PREVIOUSLY PUBLISHED IN DIVERSITY AND EQUALITY IN HEALTH AND CARE (FORMERLY DIVERSITY IN HEALTH AND SOCIAL CARE)}

We have not previously published papers about mental health in children, but we have carried the following articles which focus on particular aspects of the lives of children and young people:

Dyson SE, Atkin K, Culley L et al (2012) School ethos and variation in health experience of young people with sickle cell disorder at school. Diversity and Equality in Health and Care 9:33-44.
Gardner K, Salah S, Leavey C et al (2010) The perfect size: perceptions of and influences on body image and body size in young Somali women living in Liverpool - a qualitative study. Diversity in Health and Care 7:23-34.

Lau M, Lin H and Flores G (2012) Primary language spoken at home and health disparities and healthcare of US adolescents. Diversity in Health and Care 9:267-80.

Stock N, Whale K, Jenkinson E et al (2013) Young people's perceptions of visible difference. Diversity in Health and Care 10:41-52.

Yu J (2008) Perspectives of Chinese British adolescents on sexual behaviour within their socio-cultural contexts in Scotland. Diversity in Health and Social Care 5:177-86.

\section{ADDRESS FOR CORRESPONDENCE}

Professor Nisha Dogra, Greenwood Institute of Child Health, University of Leicester, Westcotes House, Westcotes Drive, Leicester LE3 0QU, UK. Tel: +44 (0)116 225 2889; fax: +44 (0)116 225 2881; email: nd13@le.ac.uk

\section{MCQs to assess understanding of this topic}

Please indicate whether each of the following statements is true or false:

Children's mental health problems are usually related to a single factor

Children whose parents have mental health problems are more likely to develop mental health problems $\mathrm{T}$

$\begin{array}{ll}\text { Less than } 10 \% \text { of children develop mental health problems } & \text { F }\end{array}$

$\begin{array}{ll}\text { Mental disorders cannot usually be successfully treated } & F\end{array}$

$\begin{array}{lc}\text { Schools may be a good place to promote child mental health } & \text { T }\end{array}$

Children from any social background can develop mental health problems $\quad \mathrm{T}$

Positive self-esteem may reduce the risk of developing mental health problems $\quad T$

Good mental health is an important part of overall health $\quad \mathrm{T}$ 
